DOI: https://doi.org/10.33103/uot.ijccce.20.2.5

\title{
In-Situ Pipeline Monitoring System Design for Identifying and Locating Damaging Activities Based on Wireless Sensor Network
}

\author{
Ahmed H. Hadi ${ }^{1}$, Waleed F. Shareef ${ }^{2}$ \\ ${ }^{1,2}$ University of Technology, Control and Systems Department, Baghdad, Iraq \\ eng.ahmed.altajer@gmail.com,60026@uotechnology.edu.iq
}

\begin{abstract}
Due to the recent advancements in the fields of Micro Electromechanical Sensors (MEMS), communication, and operating systems, wireless remote monitoring methods became easy to build and low cost option compared to the conventional methods such as wired cameras and vehicle patrols. Pipeline Monitoring Systems (PMS) benefit the most of such wireless remote monitoring since each pipeline would span for long distances up to hundreds of kilometers. However, precise monitoring requires moving large amounts of data between sensor nodes and base station for processing which require high bandwidth communication protocol. To overcome this problem, InSitu processing can be practiced by processing the collected data locally at each node instead of the base station. This Paper presents the design and implementation of In-situ pipeline monitoring system for locating damaging activities based on wireless sensor network. The system built upon a WSN of several nodes. Each node contains high computational $1.2 \mathrm{GHz}$ Quad-Core ARM Cortex-A53 (64Bit) processor for In-Situ data processing and equipped in 3-axis accelerometer. The proposed system was tested on pipelines in Al-Mussaib gas turbine power plant. During test knocking events are applied at several distances relative to the nodes locations. Data collected at each node are filtered and processed locally in real time in each two adjacent nodes. The results of the estimation is then sent to the supervisor at base-station for display. The results show the proposed system ability to estimate the location of knocking event.
\end{abstract}

Index Terms - WSN, In-Situ monitoring system, Pipeline Monitoring, MEMS, Localization.

\section{INTRODUCTION}

Nowadays, many methods have been already used to build Pipeline Monitoring Systems (PMS), which depend on sensing methods like Visual inspection, Ultrasound, Radiographic, Thermography, Pressure, Chemical and Magnetic. Other projects introduced PMS depending on Satellite, Smart Pigging, Drones, Smart Robots, and Dogs [1]. In situ data management (ISDM) consists of the procedures to control the streams of data and enable the coordination of and communication among applications, executing simultaneously in PMS, cooperating toward an event detection and localization [2].

Wireless Sensor Network (WSN) became more reliable option for monitoring with the development of MEMS sensors in the recent years, because MEMS offer small size, low cost, and ease of operation [3]. The definition of Wireless Sensor Network is an infrastructure that allows remote (interconnection, sense, and control) of the objects depending on a group of dedicated sensors for monitoring and recording the physical condition of the environment and organize the collected information at a central location. Sometimes, WSNs are static network where static nodes installed. In 
this case, the goal of WSN is to sense, combine, and process the data of sensor nodes on-site. The localization algorithm in this type is used to get distance or angle and it can be categorized into two category as range-based or range-free [4].

Designing a monitoring system for pipeline has been an active field in the recent years with many research groups tackle different aspects of the monitoring process. In [5] PipeNet project for Leak Detection and Localization. Several signal processing algorithms have been performed like wavelet transform, cross correlation, recognition of patterns; a sensor node hardware built by Intel mote, ARM7 core, and Bluetooth communication. Another project named, PipeProbe [6] built by EcoMote and a tiny pressure sensor dropped inside water pipeline, the system design is to work inside walls made by cement or underground water pipelines where inspection is very difficult. PipeProbe gathers two type of sensors that are accelerometer and water pressure. SPAMMS [7] is a WSN for PMS to Control and Localize the Leak in water pipeline using robot, static, and mobile nodes where some kinds like chemical, pressure and sonar sensor that are used depending on ATMega103 Microcontroller, and RFID. Novel leakage detection and graph localization for water distributed network (WDN) was introduced in [8] depending on One-Dimensional Convolutional Neural Networks and Support Vector Machine (1D-CNNs-SVM) to extract the features, classifiers, and reduce learning time. The system uses a graph-based local search algorithm to select the nearest estimated leakage location. In [9] a simulator and geographical information system used to build a framework of single or multiple irregularity pipeline's localization by two detection techniques: Negative pressure wave and pressure point analysis. The acoustic detection where the sensors are installed at both ends of pipes where the leak may be occur, then depending on a Velocity of Sound Propagation, sensing point distance and lagging time, to calculate leak location. In [10] signals of monitoring system processed by wavelet transform to extract the characteristic parameters. The first step is a recognition phase, then a multi classifier mode which performed by Support Vector Machine, and then to determine the leak's position, a weighted average localization algorithm depending on time difference of arrival (TDOA) introduced. In [11] the difficulties of communications and analysis illustrated for underground WSN, by examining the effects of environment parameters. The study approved that WSN can take a good effects when the work underground is as same as the overground. LAN server and Raspberry Pi used in [12] for intelligent garbage monitoring method by using gas sensor, ultrasonic sensor, load cell, and moisture sensor. A similar design to detect and localize the leakage in water pipeline [13] depending on vibration signal but the difference is that data collected and sent to offline analysis at base station while our system design work as In-situ to collect and analyze data then it gains time and cost. In [14], VibNet is introduced based on WSN for vibration monitoring. Triple axis vibration sensor ADXL335 used for acceleration measurements, sensing method depending on the received signal strength indicator (RSSI) algorithm while the communication section implemented by Zigbee transceiver.

Table 1 presents comparative keynotes of selected related work and the proposed system regarding the sensors used, the communication protocol, and the data analysis method.

TABLE 1 COMPARATIVE ANALYSIS BETWEEN DIFFERENT PMS WITH THE PROPOSED SYSTEM.

\begin{tabular}{ccccc}
\hline Name & Type of Sense & Sensor name & $\begin{array}{c}\text { Protocol \& } \\
\text { Communication used }\end{array}$ & $\begin{array}{c}\text { Data } \\
\text { Analysis }\end{array}$ \\
\hline VibNet [14] & Vibration \event detection & $\begin{array}{c}\text { ADXL335 }- \text { max } \\
\text { acceleration up to }+/-3 \mathrm{G}\end{array}$ & UART / Zigbee & Off-line \\
$\begin{array}{c}\text { Mossa N. } \\
\text { [16] }\end{array}$ & Vibration \event identification & $\begin{array}{c}\text { ADXL345 }- \text { max } \\
\text { acceleration up to }+/-16 \mathrm{G}\end{array}$ & $\mathrm{I}^{2} \mathrm{C} /$ Zigbee & Off-line \\
$\begin{array}{c}\text { Proposed } \\
\text { system }\end{array}$ & $\begin{array}{c}\text { Vibration \event Identification } \\
\text { \& localization }\end{array}$ & $\begin{array}{c}\text { ADXL345 }-\max \\
\text { acceleration up to }+/-16 \mathrm{G}\end{array}$ & $\mathrm{I}^{2} \mathrm{C} / \mathrm{WiFi}$ & On-line \\
\hline
\end{tabular}




\section{OIL PIPELINE SPECIFICATIONS}

There are two general types of pipelines, Gathering lines are 10-30 $\mathrm{cm}$ in diameter and used for short distance to transport gas or crude oil, and Feeder lines used to transport gas or crude from storage tanks and processing units to transmission pipes. Another classification of pipelines are Natural Gas pipeline and Liquid Petroleum Pipeline. Iraq has a wide pipelines network used to transport a crude oil and natural gas from the oil fields to refineries, storage tanks, and oil export platforms in Basra (south of Iraq) [15].

Tests conducted in this paper used a pipeline with plain ends, on-ground type that made from carbon steel and special coatings applied to its outside to increase protection from corrosion and abrasion. It is used locally to transfer crude oil between storage tanks and refinery or Power Plant. Pipeline dimensions range from $25 \mathrm{~mm}$ to $350 \mathrm{~mm}$ duo to its usage. The thickness of the pipe's wall is comparative to its outer and inner diameter. The descriptions of the tested pipe used in this experiment shown in Table 2 [16].

TABle 2. Oil Pipeline Specifications

\begin{tabular}{|l|l|}
\hline Pipeline Product & Crude oil \\
\hline Ends Type & Plain Ends \\
\hline Type of Pipe & Carbon Steel \\
\hline Wall Thickness & $6.3 \mathrm{~mm}$ \\
\hline Outer Diameter & $219.1 \mathrm{~mm}$ \\
\hline
\end{tabular}

\begin{tabular}{|l|l|}
\hline Interval Between each Support & $3.5 \mathrm{~m}$ \\
\hline Length & $50 \mathrm{~m}$ \\
\hline Height & $8 \mathrm{inch}$ \\
\hline Weight & $14.78 \mathrm{~kg} / \mathrm{m}$ \\
\hline Inner Diameter & $213.56 \mathrm{~mm}$ \\
\hline
\end{tabular}

\subsection{DETERMING THE PIPELINE NATURAL FREQUENCY}

Knowing pipe dimensions and specifications is essential in determining its natural frequency. To perform a vibration tests on a certain system, the most important thing is to calculate the natural frequency of that system which equal to the freedom numbers. In time domain, the amplitude of any vibration force refers to one frequency or small number of frequencies. Therefore, a calculation of the natural frequency solve the restriction of free vibration for any system.

The system may have more than one natural frequency, but the lowest one is chosen because it represents more importance to the others. So, the natural frequency of the tested pipeline can be calculated prior to any outer force applied by the following equation [17]:

$$
\mathrm{F}_{\mathrm{n}}=\frac{1}{2 \pi} \cdot 22 \cdot 4 \cdot \sqrt{\frac{E I}{\mu L^{4}}}
$$

Where:

$F n$ : natural frequency of the pipe in $(\mathrm{Hz})$

$E$ : Young's modulus of elasticity (200GPa or 30E6psi for steels)

$I$ : fourth polar moment of inertia $\left(0.049^{*}\left[\mathrm{OD}^{4}-\mathrm{ID}^{4}\right]\right)$. Where OD and ID is Outer and Inner Diameter.

$\mu$ : pipe mass per unit length lbs. /inch or $\mathrm{kg} / \mathrm{m}$.

$L$ : the intervals between pipe upholding.

Referring to information in Table 2 and the Eq.1, the natural frequency of the tested pipe in this experiment is approximately $113 \mathbf{~ H z}$.

\subsection{DETERMING THE REUQIRED SAMPLING RATE}

According to Shannon Sampling theorem, If a continuous time signal contains no frequency components higher than $W \mathrm{~Hz}$, then it can be completely determined by uniform samples taken at a rate $f$ s samples per second where:

$$
f \mathrm{~s} \geq 2 \mathrm{~W}
$$

or, in term of the sampling period: 


$$
\mathrm{T} \leq 1 / 2 \mathrm{~W}
$$

A signal with no frequency component above a certain maximum frequency known as a band-limited signal. The minimum sampling rate allowed by the sampling theorem $(f \mathrm{~s}=2 W)$ is called the Nyquist rate.

To choose a suitable hardware component (Microprocessors, Sensors, and communication part), the sampling frequency must be determined first. Depending on Shannon theorem [18] "The minimum sampling rate equals to two samples per period of the maximum frequency component for signal", Eq.2 and Eq.3, Therefore, the minimum sampling rate to get the natural frequency of the chosen pipe is $226 \mathrm{~Hz}$. In this paper, the sampling frequency recorded to $400 \mathrm{~Hz}$ as explained in Section 4.

\section{DESIGN OF SENSOR NODE}

Mainly, there are four subsystems for the node design described in Figure 1, which are Power supply subsystem, Processing subsystem, Sensing subsystem, and Communication subsystem. Batteries or Solar are however the most frequently used power suppliers because of their functions of low cost, tiny size, long life, and high capacity. Therefore the power unit built by batteries. The function of the processing subsystem is to register stream of data, process it through a microcontroller or microprocessor and store it in memory. Any phenomenon occurs in the field of interest is detected and registered by an appropriate sensor which transform this phenomenon to an analog signal depending on its hardware structure. The analog signal then converted by Analog to Digital Convertor (ADC) then the digital signal is handled by the processor. The remaining part of the hardware of wireless sensor node is the communication subsystem that is responsible of data transmitting and receiving over a $\mathrm{WiFi}$.

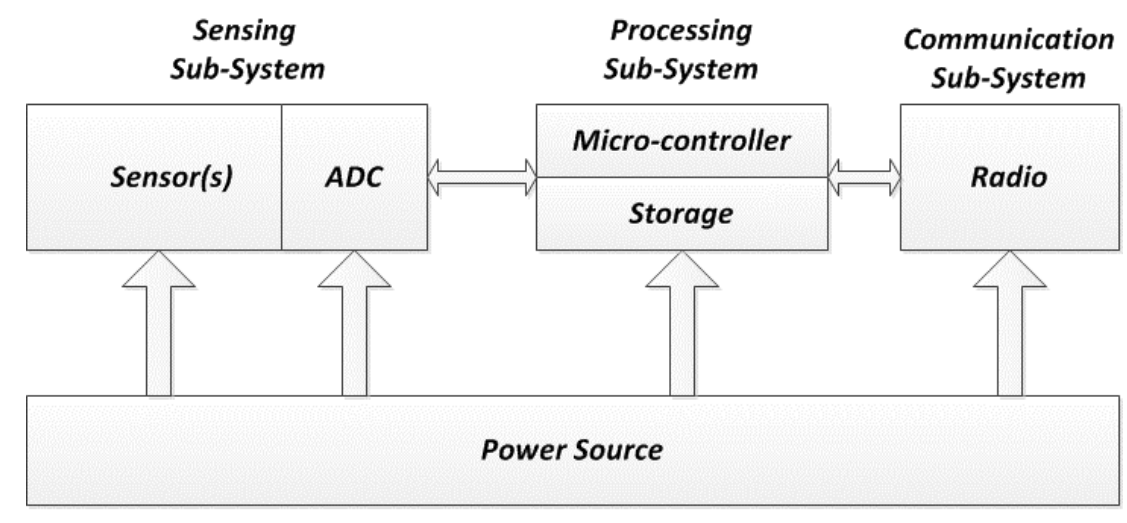

Power Supply Sub-System

Fig.1. Wireless Sensor Node ArChitecture

\subsection{SENSOR SELECTION: ACCELEROMETER}

The decision to select proper accelerometer is very critical because it is widely utilized for fault detection in many machines due to their reliable operation, precision, and sensitivity [16]. They are MEMS (Micro-electro-mechanical-sensors) instruments that switch the mechanical signal, such as vibration to electrical signal. Through variable type of MEMS accelerometer, ADXL345 was selected because it meets the requirements of In-Situ Monitoring System. In addition, it is widely used in the vibration and motion fields. Table 3 shows a comparison between multiple types of accelerometer. 
TABle 3 Comparison of Multiple Vibration SEnSOrS

\begin{tabular}{|c|c|c|c|c|}
\hline Technology & $801 S$ & LDT0-028K & Piezoelectric & ADXL345 Accelerometer \\
\hline Reliability & Low & Low & Low & High \\
\hline $\begin{array}{l}\text { Shock } \\
\text { \&vibration } \\
\text { Resistance }\end{array}$ & $60,000,000$ shocks & Withstands High impact & $\begin{array}{l}\text { Max. Pressure can } \\
\text { applied } 1000 \text { PSI }\end{array}$ & $10,000 \mathrm{~g}$ shocks \\
\hline $\begin{array}{c}\text { Operating } \\
\text { Temperature }\end{array}$ & None & $0^{0}-85^{0} \mathrm{C} \max$ & -50 to $350{ }^{\circ} \mathrm{C}$ & $-40^{\circ} \mathrm{C}$ to $+85^{\circ} \mathrm{C}$ \\
\hline Resolution & Low & Low & Low & Scalable \\
\hline Cost & $\$++$ & $\$++$ & $\$$ & $\$+$ \\
\hline $\begin{array}{c}\text { Embedded } \\
\text { Memory } \\
\text { Management } \\
\text { System }\end{array}$ & No & No & No & $\begin{array}{l}\text { FIFO technology minimizes } \\
\text { host processor load }\end{array}$ \\
\hline Size & $\begin{array}{c}(20 \times 32 \times 11) \\
\mathrm{Mm}\end{array}$ & $\begin{array}{c}28 \mu \text { mthick } \\
\text { polymer film, } \\
\text { laminated to } \\
0.125 \mathrm{~mm} \text { polyester }\end{array}$ & $\begin{array}{c}(18 \times 9 \times 0.21) \\
\mathrm{mm} .\end{array}$ & $\begin{array}{l}\text { Small and thin: } \\
(3 \times 5 \times 1) \mathrm{mm} \\
\text { LGA package }\end{array}$ \\
\hline Need filter output & Yes & Yes & Yes & $\begin{array}{l}\text { Contain embedded digital } \\
\text { filter }\end{array}$ \\
\hline $\begin{array}{l}\text { Measurement } \\
\text { range }\end{array}$ & $\begin{array}{l}\text { Vibration } \\
\text { detection } \\
\text { range, non- } \\
\text { directional }\end{array}$ & $\begin{array}{l}1000 \mathrm{~Hz} \\
\text { maximum }\end{array}$ & $\begin{array}{l}\text { from } 20 \mathrm{~Hz} \text { to } \\
\qquad 10 \mathrm{KHz}\end{array}$ & $\begin{array}{l}\text { From } 0.1 \mathrm{~Hz} \text { to } \\
\quad 3200 \mathrm{~Hz}\end{array}$ \\
\hline
\end{tabular}

The triple-axis digital accelerometer ADXL345 [19] is shown in Figure 3, it is developed by Analog Devices company. It is tiny, slim, and ultralow power range between $23 \mu \mathrm{A}$ when measurements mode selected and $0.1 \mu \mathrm{A}$ when standby mode selected. The supply voltage range ( 2.0 - 3.6 volt), tworesolution mode selection: 10 bit with ranges of $+/-2 \mathrm{G},+/-4 \mathrm{G}$, and $+/-8 \mathrm{G}$, and 13-bit resolution up to $+/-16 \mathrm{G}$ (where $\mathrm{G}$ is the acceleration gravity of the earth equals to $9.807 \mathrm{~m} / \mathrm{s}^{2}$ ). Data rate output between 0.1 and $3200 \mathrm{~Hz}$. Therefore, it is selected because it highly covers twice the natural frequency of the proposed system in this mission.

\subsection{MICROCONTROLLER SELECTION}

Using microcontroller to host sensors is an economic solution to design a sensor network. However, when data analysis needs more computing than Microcontroller provides, microprocessor is preferred. In addition, microprocessor is able to deal with several data format, data structures, and display devices. The huge amount of data that to be collected and analyzed requires computer - based calculations . All these situations need a computer that has more processing power, allow common applications, and permit the use of programming languages easily. Although PC is inexpensive, there is disadvantage to use it if the sensors are located in areas where the main power is unavailable or there is a danger of overheating, or there is no place to install PC, and PC has no general I/O ports [20]. Raspberry Pi 3 Model B shown in Figure 3 is an open source, low cost computer with excellent processing power and memory that used standard peripherals, and supported programmable I/O. Raspberry Pi brings the good features of PC to the scope of sensor network that makes it the perfect platform for interfacing with wide variety of external peripherals [21]. 


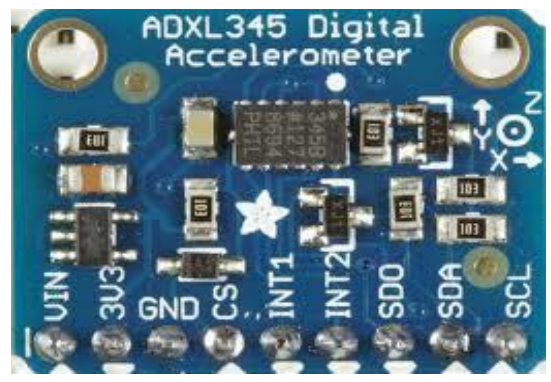

FIG.2 ADXL345 ACCELEROMETER

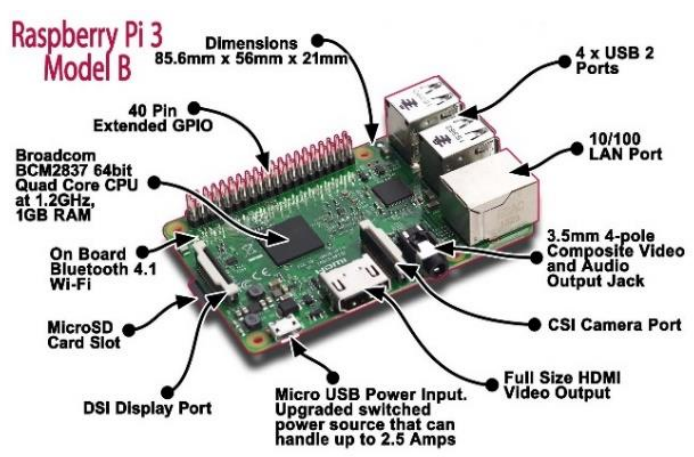

Fig.3 RASPBERRy Pi 3 MOdel B

\subsection{ACCELEROMETER OFFSET CALIBRATION:}

ADXL345 is a mechanical structure and that contains some parts that are free to move, these parts are very sensitive. Offset must be calculated at first and written to the three offset registers. The calibration method is done by taking (10) readings at start reading and then get the average of it which will be the offset of $\mathrm{X}, \mathrm{Y}$, and $\mathrm{Z}$, finally subtract the measured value from the average or offset of each axis to get actual reading .(Eq.4) [15].

$$
\left.\begin{array}{r}
\mathrm{X}-A C T U A L=\mathrm{X}-\mathrm{MEAS}-\mathrm{X} 0 \mathrm{~g} \\
\mathrm{Y}-A C T U A L=\mathrm{Y}-\mathrm{MEAS}-\mathrm{Y} 0 \mathrm{~g} \\
\mathrm{Z}-\mathrm{ACTUAL}=\mathrm{Z}-\mathrm{MEAS}-\mathrm{Z} 0 \mathrm{~g}
\end{array}\right\}
$$

Where: MEAS is sensor measurement

\section{SYSTEM SETUP}

The proposed system is shown in Figure 4. It consists of two sensor nodes attached at the end of $50 \mathrm{~m}$ carbon steel, plain ends oil pipe. The sensor of Node No. 1 attached at 1 meter from right end beside of the pipe while the sensor of Node No. 2 attached to the other end at 49 meter as shown in Figure 4. Both sensors were attached to the pipe using duct tape. There are eight concrete stands installed every $6 \mathrm{~m}$ to support the pipe. In the site, experiment was conducted in three different scenarios:

1. Scenario \#1: conducted to compare sensor measurements with and without event on the pipe.

2. Scenario \#2: involve applying continuous knocking event on the pipe at rate $1 \mathrm{knock} / \mathrm{sec}$.

3. Scenario \#3: involve applying continuous knocking event on the pipe at rate $2 \mathrm{knock} / \mathrm{sec}$.

Scenario 2 and 3 have five cases each, for five different distances. Each case was repeated four times to grantee test repeatability. Hence each scenario produced 20 sets of data. Knocking event (using handheld hammer) was applied at 1, 12, 24, 36, 48 meter measured from the right end of the pipe (node 1) as shown in Figure 5. Knocking event selected to emulate a group of on-ground pipe damaging activities as (drilling, punching, forklift working, etc.).

The proposed system focuses on detecting the event and finding its location. Each node collects data for a short period of time (14 seconds) of live vibration readings resulting from hammering activities on different distances. The node analyzes the data locally, and sends the decision about the activity and its location to the supervisor at base-station through wireless connection (Wi-Fi), since each node is equipped with RF unit and can act as an access point. 

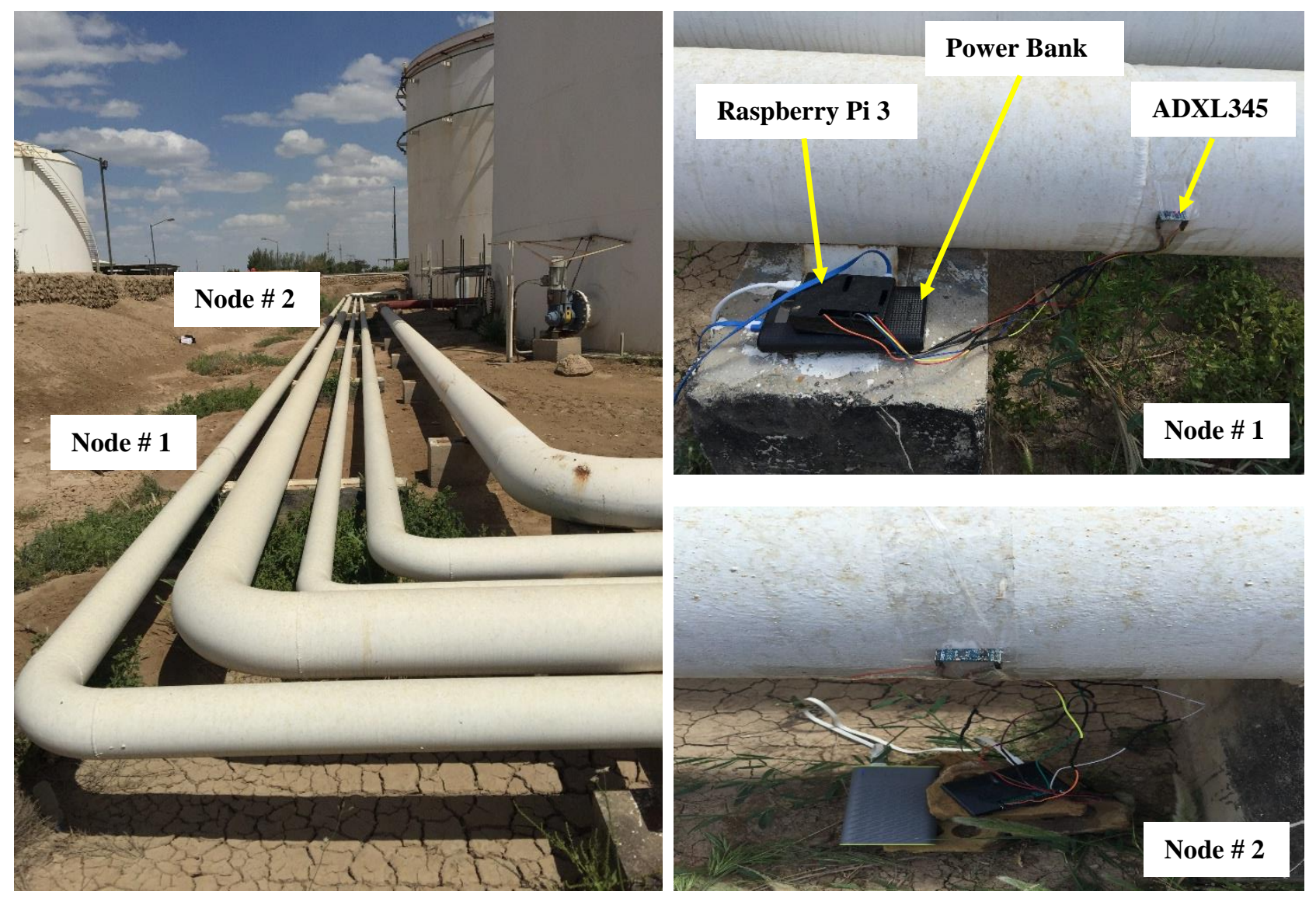

FIG. 4 ACCELEROMETER LAYOUT ON THE PIPE

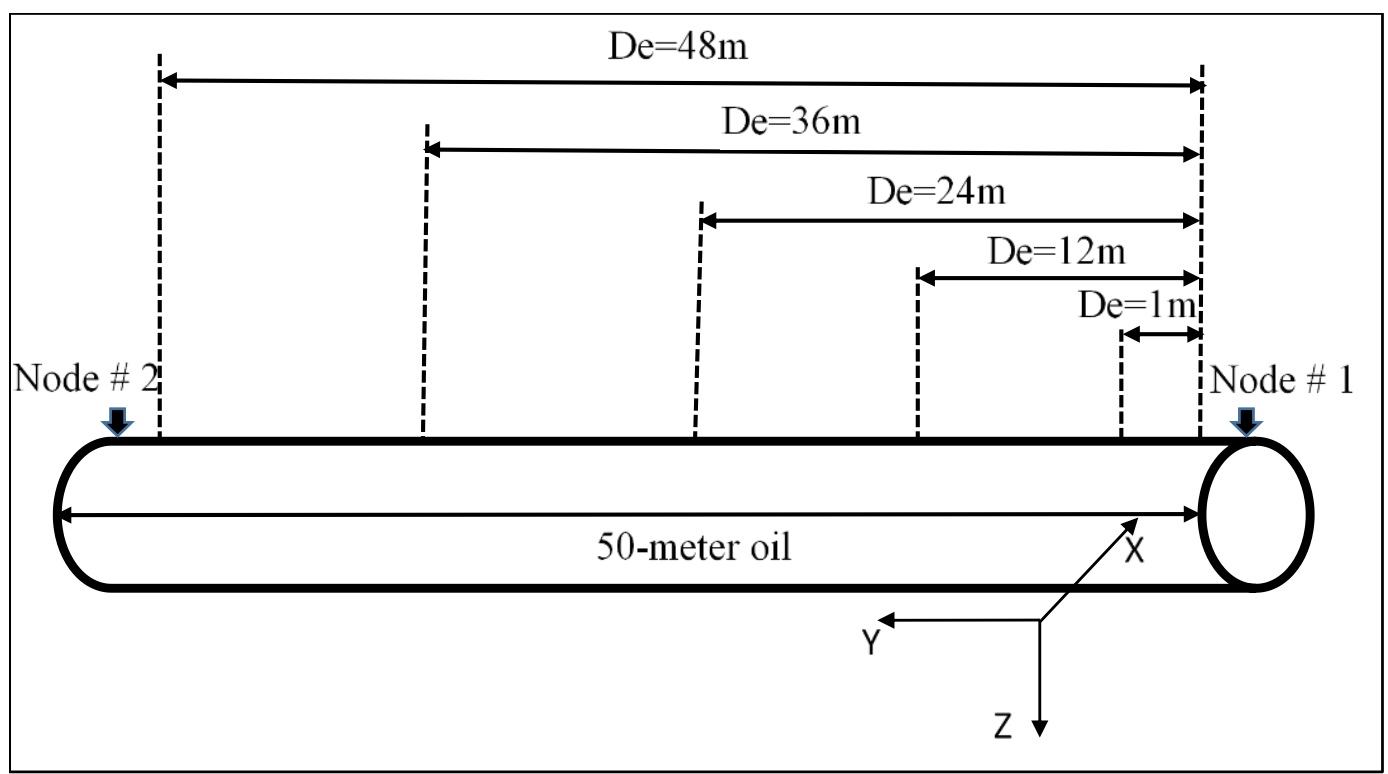

Fig. 5 Distances (DE) AT Which the DAMAging EVENTS ARE APPLIED

\section{RESULTS AND DISCUSSIONS}

The measurements of each scenario are analyzed to find a general form for event localization on the pipeline with different locations of the damaging event. Measurements from the three axis where approximately similar as shown in Figure 6. However, $\mathrm{X}$-axis measurement was higher than the $\mathrm{Y}$ and 
$\mathrm{Z}$ axes measurements. For the $\mathrm{Y}$-axis, this is because the $\mathrm{Y}$-measurements depend on the vibrational signal propagating parallel to the pipeline and perpendicular to the damaging event. On the other hand, the $\mathrm{Z}$-axis measurements were damped by the stands that held the pipe in its place.

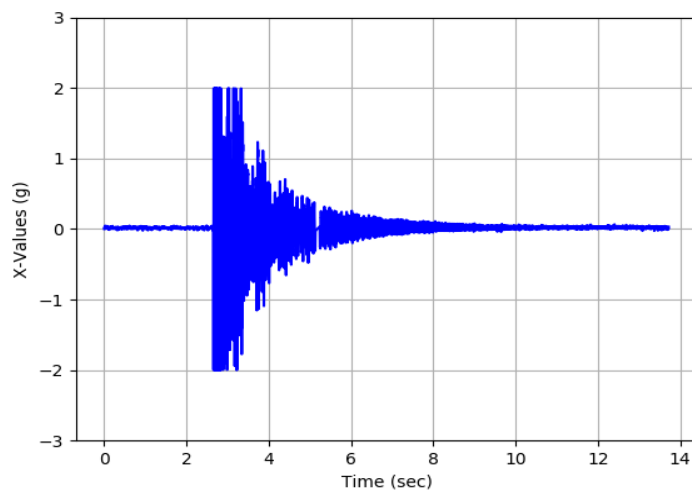

(a) $X$-axis measurements

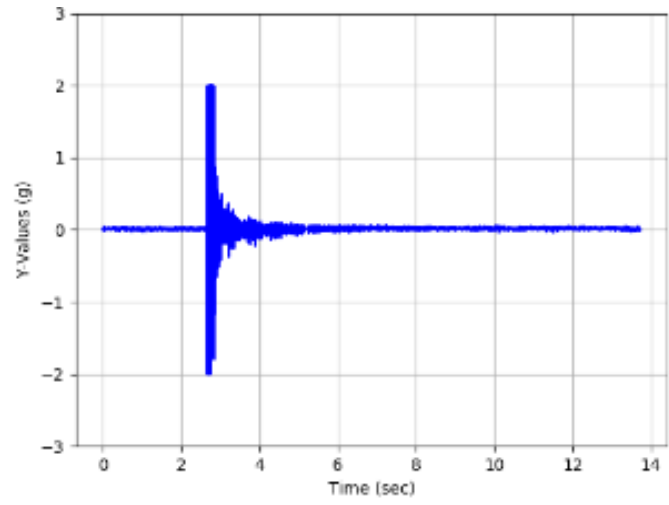

(b) Y-axis measurements

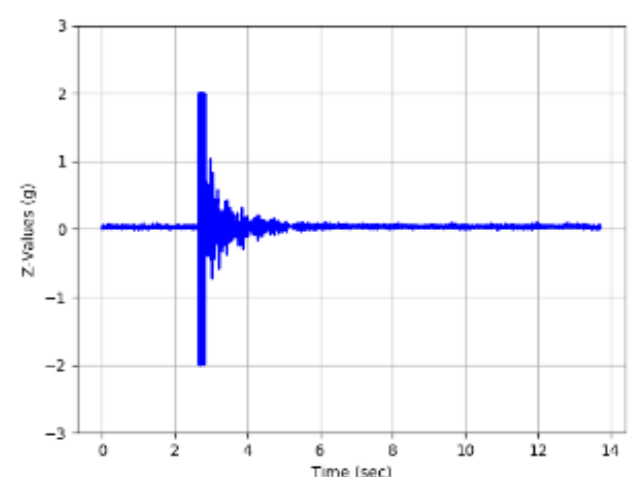

(c) Z-axis measurements

Fig.6 ACCELEROMETER X, Y, Z- AXIS MEASUREMENTS

\subsection{SCENARIO \#1 Tests With and Without Event on the Pipe:}

First, the accelerometer (vibration) measurements were collected at nodes without any damaging activities applied on the pipe; this is a healthy or normal case for oil pipeline monitoring system.

Then, $1 \mathrm{Kg}$ weight was dropped from 1 meter height, on the pipe 1 meter away from the sensor node location. This scenario is used as a reference to the force of subsequent scenarios. Figure.7 shows the $\mathrm{X}$-axis measurements of the sensor for both cases in this scenario. The figure also shows the $\pm 2 \mathrm{~g}$ range of the accelerometer is adequate for detecting and processing the signal. 

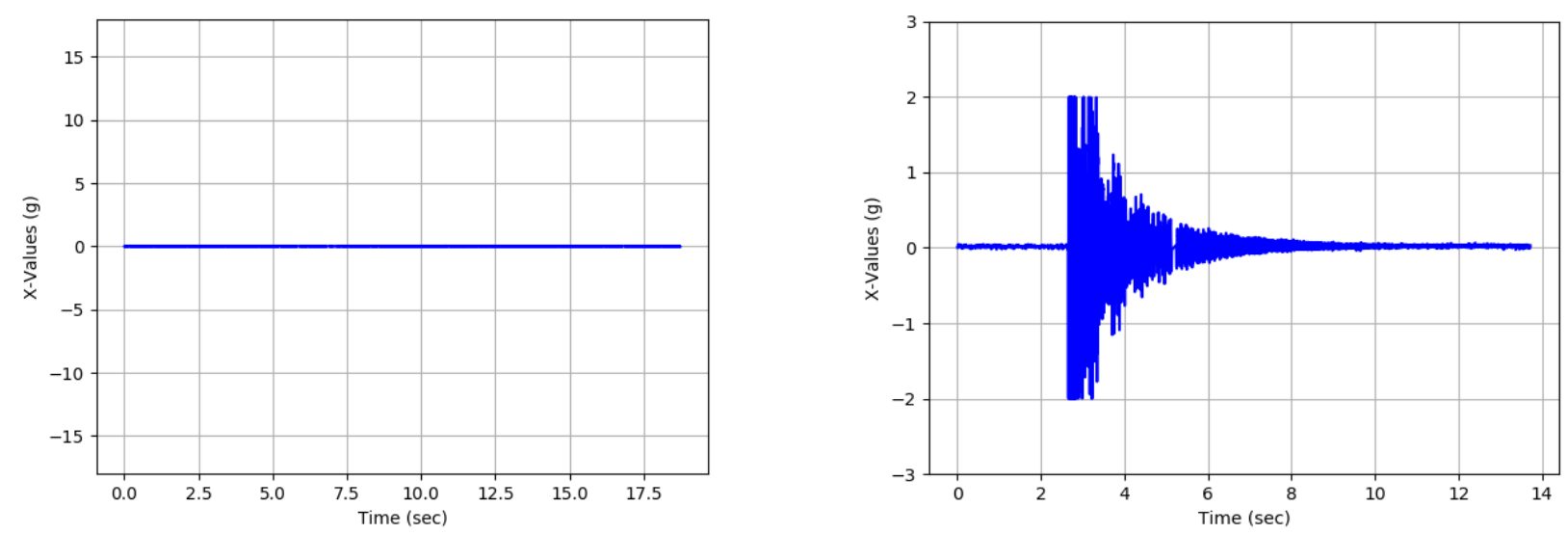

Fig.7 ACCELEROMETER X-AXIS MEASUREMENTS In SCENARIO \# 1 LEFT: Without EVENT, Right: With EVENT

\subsection{SCENARIO \#2 Test with knocking rate of one knock per second:}

This scenario was implemented by knocking the pipe from the top by hammer, eight knocks are applied at a rate of one knock per second in five cases. In each case, different location on the pipeline is selected as illustrated in Table 4.

TABLE 4 KNOCKING LOCATIONS OF SCENARIO \#2

\begin{tabular}{cc} 
CASE NUMBER & DISTANCE DE \\
\hline $\boldsymbol{C A S E}$ \# 1 & $1 \mathrm{~m}$ \\
$\boldsymbol{C A S E}$ \# 2 & $12 \mathrm{~m}$ \\
$\boldsymbol{C A S E}$ \# 3 & $24 \mathrm{~m}$ \\
$\boldsymbol{C A S E}$ \# 4 & $36 \mathrm{~m}$ \\
$\boldsymbol{C A S E}$ \# 5 & $48 \mathrm{~m}$
\end{tabular}

Figure 8 shows $\mathrm{X}$-axis measurements response with time for Scenario \#2. The results show that although the initial amplitude of the response is approximately the same for all the distances ( the amplitude is saturated at \pm 2 ), the rate at which the signal diminish is different in each case. At larger value of event distance $(D e=48)$, the response diminish faster than the response at smaller value of $(D e=1)$. For $1 \mathrm{~m}$ distance the response continues to several seconds after the event (the knock) while for $D e=48 \mathrm{~m}$ the response is diminished to rest value within fraction of a second.
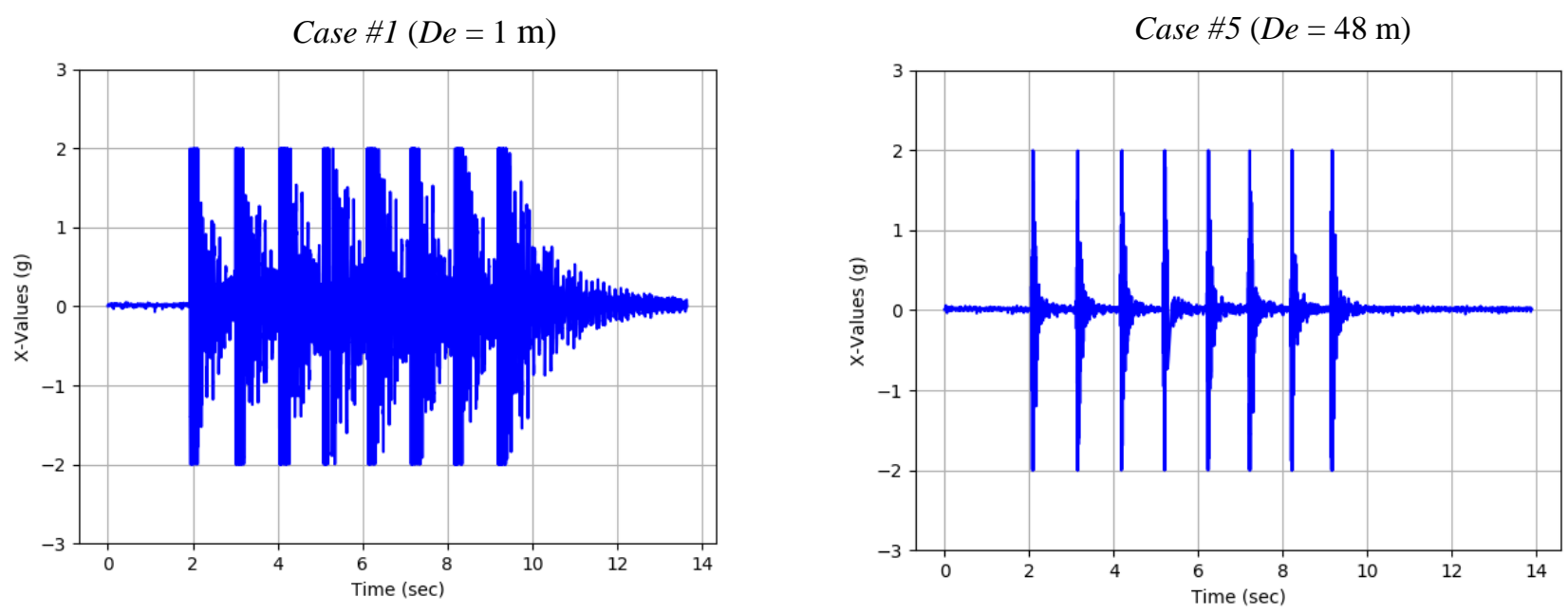

Fig. 8 ACCELEROMETER X-AXIS MEASUREMENTS IN SCENARIO \# 2 


\subsection{SCENARIO \#3 Test with knocking rate of two knock per second:}

In this scenario eight knocks are applied to the pipeline at rate of 2 knocks per second approximately. The scenario is also repeated for several event distance $D e$ as shown in Table 4.

Similar to previous scenario, the results show that the response for higher value of $D e$ diminish is faster than the response for lower value of $D e$. In addition, Results of this scenario (shown in Fig 9) show that the response at different distance is still recognized even for high rate of applied knocks.
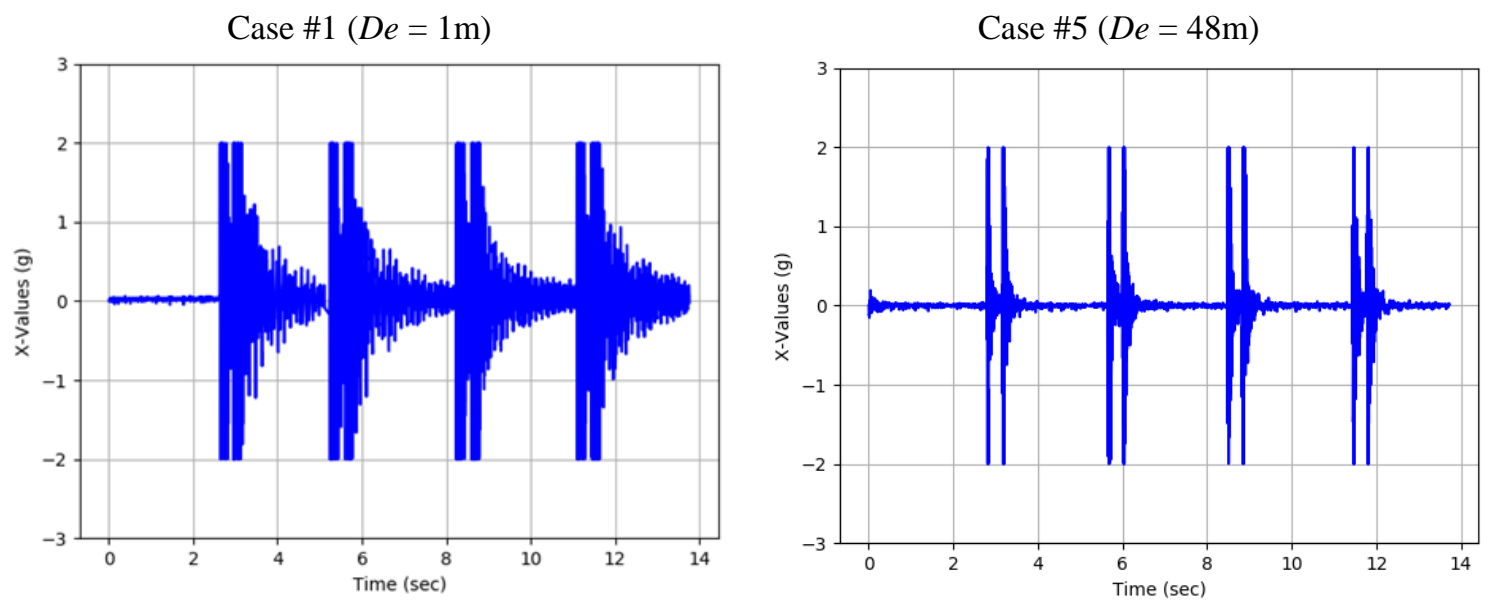

Fig. 9 AcCelerometer X-AXis Measurements in Scenario \# 3

\subsection{Estimation of Event Location:}

From the previous results, it is clear that the response in time domain shows that the vibration signal takes a long time to fall from maximum value to the rest value (approximately zero) at longer value of $D e$. To estimate event distance relative to node location an approximation of the signal diminishing speed must be obtained. First the measurements are collected from the accelerometer, then the signal is filtered by removing the outliner values. The negative part of the signal is also removed since the signal is symmetrical around the $\mathrm{X}$-axis. Then envelope of the signal is calculated. Fig 10 lists the processing algorithm steps, while Fig 11 shows the envelope of the signal response for $D e=1 \mathrm{~m}$ and $D e=48 \mathrm{~m}$ respectively. 


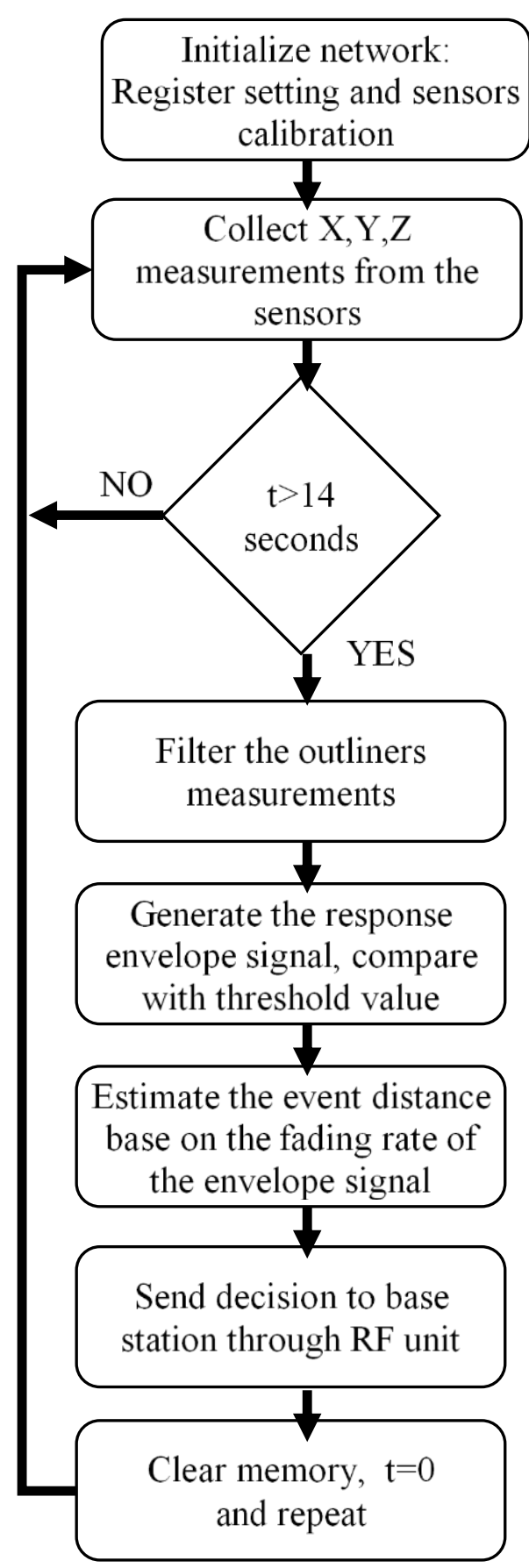

FIG. 10 PROPOSED SYSTEM FLOWCHART 

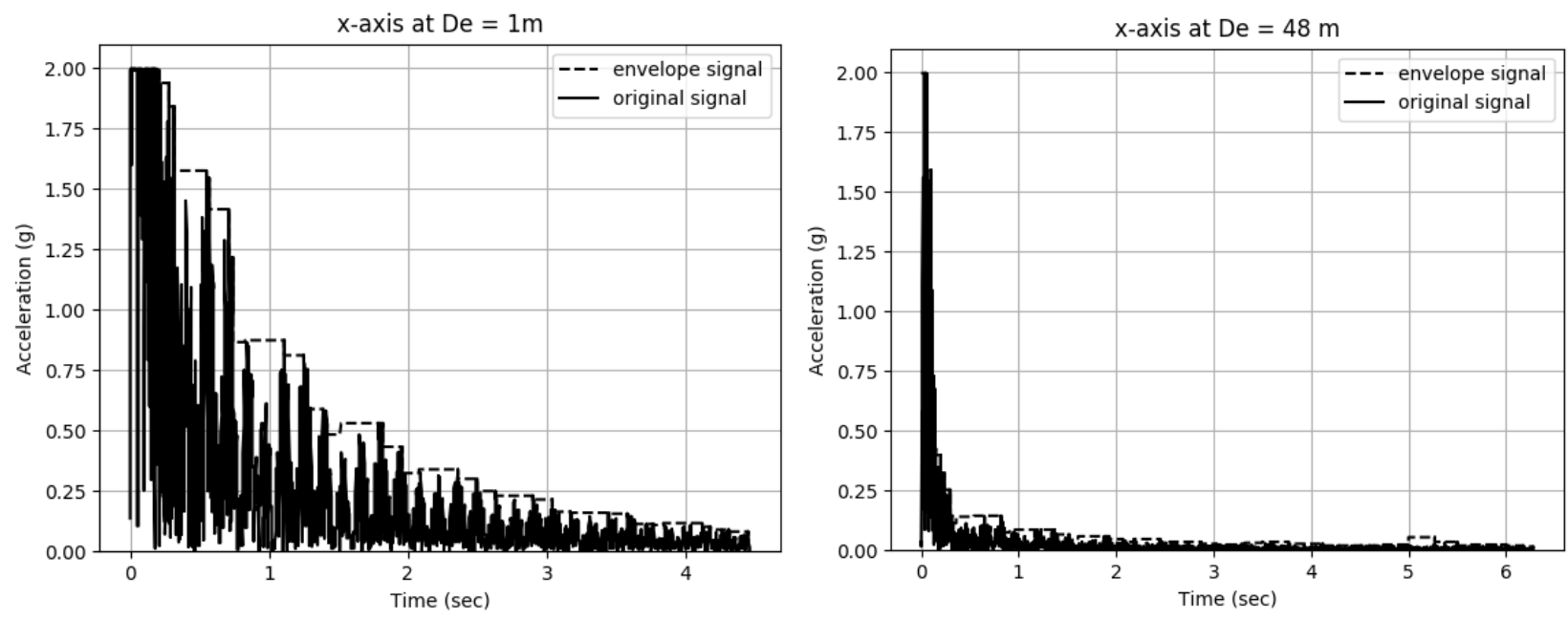

Fig. 11 MEASurements of X-AXIS (LeFT DE=1 M, RIGHT De=48 M)

All the responses from Scenario 2 are analyzed with the same process as mentioned above and the envelopes of these signals are shown in Figure 12. As expected, the figure shows that the slower falling of signal from maximum acceleration $(+2)$ to the zero would be that of knocking event at 1 meter, while the other cases show that the signal fall faster to reach zero value as De increase. At $\mathrm{De}=48$, the response shows the fastest falling rate. Threshold value is taken at acceleration $=0.4 \mathrm{~g}$ to distinguish between different cases. Moreover, by comparing the time that each response hits the threshold, the event distance De can be estimated, as shown in Table 5. For example fastest falling signal (knocking at $\mathrm{De}=48 \mathrm{~m}$ ) would have a lower value of time (approximately equal to 0.6 second) while at $\mathrm{De}=12 \mathrm{~m}$, the corresponding time value increased to approximately 1.3 second. The signal of knocking at $\mathrm{De}=1 \mathrm{~m}$ would have the largest value among the cases.

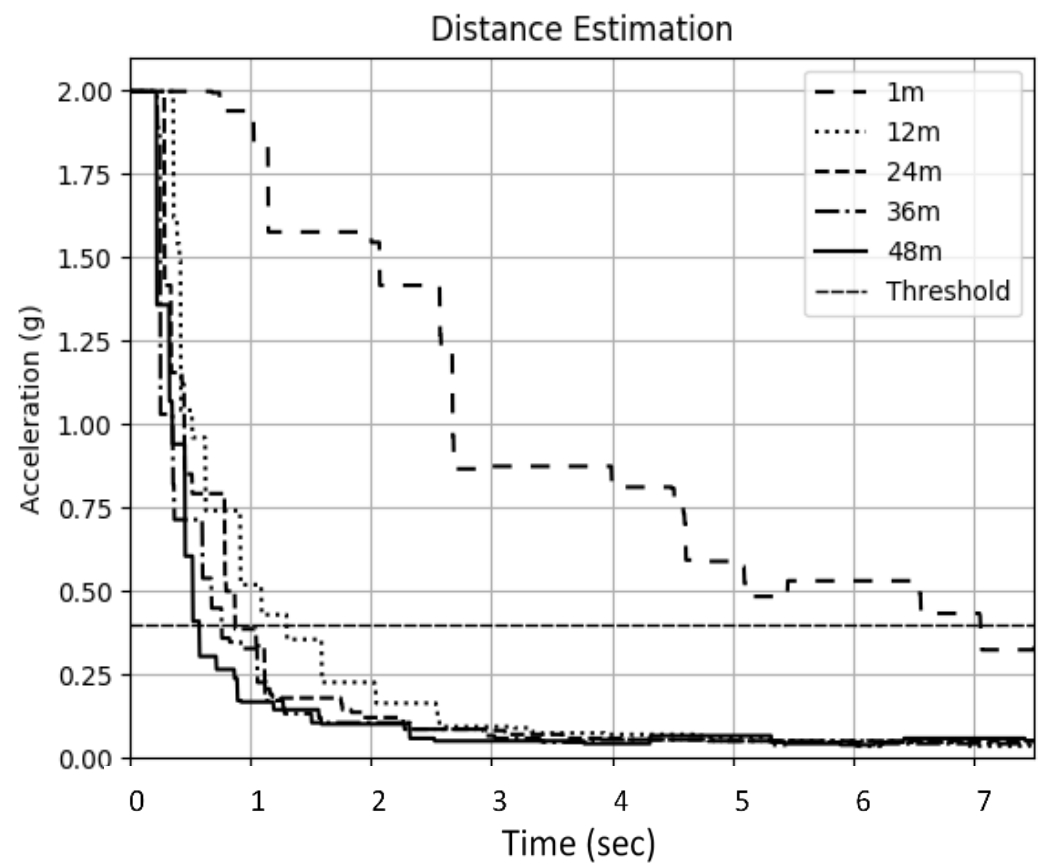

Table 4: Time corresponds to threshold $=0.4 \mathrm{~g}$

\begin{tabular}{|c|c|}
\hline $\begin{array}{c}\text { De } \\
\text { (meter) }\end{array}$ & $\begin{array}{c}\text { Time } \\
\text { (second) }\end{array}$ \\
\hline 1 & 7.1 \\
\hline 12 & 1.3 \\
\hline 24 & 0.9 \\
\hline 36 & 0.8 \\
\hline 48 & 0.6 \\
\hline
\end{tabular}

Fig. 12 Distance Estimation of Five Knocking Locations

It is worth noticing that when the event distance $D e$ increased, the interference between responses is increased. This can be seen in Table 5, where $\mathrm{T}_{\text {thr }}$ is above 7 seconds for $\mathrm{De}=1 \mathrm{~m}$, it is below 2 seconds for all the other cases. This is because the propagation of the knocking signal toward two nodes is 
attenuated exponentially along the pipe, i.e. the larger De is the larger the attenuation applied to the signal. By decreasing average distance between the WSN nodes, the signal to noise ratio (SNR) increased [22]. In addition, when the distance between two adjacent nodes increased it requires more transmission power, which affect the monitoring system privacy. So when design of WSNs, shortrange transmission should be considered to reduce eavesdropping and attenuation as well as minimize power consumption. Hence, it is recommended to splitting up large distances between nodes into several shorter distances.

\section{CONCLUSION}

The proposed In-Situ oil pipeline monitoring system uses a network of several nodes equipped with vibration sensor and high computational processor for In-Situ processing of the collected data. By implementing all the processing inside the same node. The system utilizes less power and transmission bandwidth, which makes the system more reliable for harsh environment. The system is able to collect vibration signal from accelerating and extracting its envelope to estimate the distance between the node location (known) and the damaging event location (unknown).

The proposed system was tested in Al-Mussaib Gas Turbine power plant (south of Baghdad). An event (knocking with hand held hammer) is applied to a pipeline at several locations and during each event, the sensors measurement is filtered and stored with time stamp to form a time response for that event.

By extracting the falling rate of each time response, the system was able to estimate the event location using basic processing. The processing involves generating an envelope for the time response and recording the time $\left(\mathrm{T}_{\text {thr }}\right)$ when it passes a certain threshold. The higher the value of $\mathrm{T}_{\text {thr }}$ corresponds to closer event location to the nodes location. The results obtained in this paper provide useful guidelines on the design of reliable In-Situ Pipeline Monitoring System based on WSN. More precise event localization can be achieved by decreasing the distances between adjacent nodes $(<10$ $\mathrm{m})$, or by using advanced data classification methods.

\section{REFERENCES}

[1] Journal, P.a.G., https://pgjonline.com/magazine/2018/September-2018-vol-245-no-9/features/leak-detection-goingto-the-dogs last accessed 28 November, 2019.

[2] Brandt, J., K. Devine, and A. Gentile. Infrastructure for in situ system monitoring and application data analysis. in Proceedings of the First Workshop on In Situ Infrastructures for Enabling Extreme-Scale Analysis and Visualization. 2015. ACM.

[3] Xie, S., Y. Hu, and Y. Wang. Weighted centroid localization for wireless sensor networks. in 2014 IEEE International Conference on Consumer Electronics-China. 2014. IEEE.

[4] Han, G., et al., Localization algorithms of wireless sensor networks: a survey. Telecommunication Systems, 2013. 52(4): p. 2419-2436.

[5] Obeid, A.M., et al., Towards realisation of wireless sensor network-based water pipeline monitoring systems: a comprehensive review of techniques and platforms. IET science, measurement \& technology, 2016. 10(5): p. 420426.

[6] Chang, Y.-C., et al. Pipeprobe: Mapping spatial layout of indoor water pipelines. in 2009 Tenth International Conference on Mobile Data Management: Systems, Services and Middleware. 2009. IEEE.

[7] Kim, J.-H., et al. SPAMMS: A sensor-based pipeline autonomous monitoring and maintenance system. in 2010 Second International Conference on COMmunication Systems and NETworks (COMSNETS 2010). 2010. IEEE.

[8] Kang, J., et al., Novel leakage detection by ensemble CNN-SVM and graph-based localization in water distribution systems. IEEE Transactions on Industrial Electronics, 2017. 65(5): p. 4279-4289.

[9] Anwar, S., et al., A framework for single and multiple anomalies localization in pipelines. Journal of Ambient Intelligence and Humanized Computing, 2018: p. 1-13.

[10] Wan, J., et al., Hierarchical leak detection and localization method in natural gas pipeline monitoring sensor networks. Sensors, 2012. 12(1): p. 189-214. 
[11] Trang, H.T.H. and S.O. Hwang, Connectivity analysis of underground sensors in wireless underground sensor networks. Ad Hoc Networks, 2018. 71: p. 104-116.

[12] Nageswari, S. and T. Saravanan, Intelligent Garbage Monitoring Method Using LAN Server and Raspberry PI. framework. 14(15): p. 16.

[13] Yazdekhasti, S., et al., Experimental evaluation of a vibration-based leak detection technique for water pipelines. Structure and Infrastructure Engineering, 2018. 14(1): p. 46-55.

[14] Hossain, N.I., S. Reza, and M. Ali. VibNet: Application of Wireless Sensor Network for Vibration Monitoring Using ARM. in 2019 International Conference on Robotics, Electrical and Signal Processing Techniques (ICREST). 2019. IEEE.

[15] https://www.britannica.com/place/Iraq/Oil-pipelines. 28-11-2019].

[16] Mossa, N.F., W.F. Shareef, and F.F. Shareef, Design of Oil Pipeline Monitoring System based on Wireless Sensor Network. IRAQI JOURNAL OF COMPUTERS, COMMUNICATION AND CONTROL \& SYSTEMS ENGINEERING, 2018. 18(2): p. 53-62.

[17] Harris, C.M. and A.G. Piersol, Harris' shock and vibration handbook. Vol. 5. 2002: McGraw-Hill New York.

[18] Marks, R.J.I., Introduction to Shannon sampling and interpolation theory. 2012: Springer Science \& Business Media.

[19] https://www.analog.com/media/en/technical-documentation/data-sheets/ADXL345.pdf. 28-11-2019].

[20] Alvear, O., et al., Crowdsensing in smart cities: Overview, platforms, and environment sensing issues. Sensors, 2018. 18(2): p. 460.

[21] https://www.raspberrypi.org/documentation/hardware/raspberrypi/README.md. 28-11-2019].

[22] Hawi, R., Wireless Sensor Networks--Sensor Node Architecture and Design Challenges. International Journal of Advanced Research in Computer Science, 2014. 5(1). 